\title{
DEVIC'S NEUROMYELITIS OPTICA ASSOCIATED WITH JUVENILE DERMATOMYOSITIS: CASE REPORT
}

Catarina Fernandes Pires (Universidade Federal do Piauí (UFPI), Teresina, PI, Brasil), Roberta Oriana Assunção Lopes de Sousa (Hospital Infantil Lucídio Portella, Teresina, PI, Brasil), Simone Soares Lima (UFPI, Teresina, PI, Brasil), Ana Teresa Spíndola Madeira Campos (UFPI, Teresina, PI, Brasil), Alzira Almeida de Sousa Castro (HILP, Teresina, PI, Brasil), Aparecida Maísa de Carvalho Gomes (UFPI, Teresina, PI, Brasil), Valério Chaves Pinto Júnior (UFPI, Teresina, PI, Brasil), Anália Fernandes Pires (UFPI, Teresina, PI, Brasil), Lorena Rodrigues Madeira Moura Fé (UFPI, Teresina, PI, Brasil), Constantin Philippe Salha (UFPI, Teresina, PI, Brasil), Rafaela Santos Martins (UFPI, Teresina, PI, Brasil), Lucas Aguiar Alencar de Oliveira (UFPI, Teresina, PI, Brasil)

\section{BACKGROUND}

Devic's neuromyelitis optica (NMO) is na Idiopathic inflammatory demyelinating and necrotizing disease characterized by predominant involvement of the optic nerves and spinal cord. Recent immunopathological evidences suggest that the target antigen is aquaporin-4, the dominant water channel in the central nervous system (CNS), located in the astrocyte foot precesses at the blood-brain barrier. In Asian countries relapsing NMO has been known as opticospinal multiple sclerosis. NMO has been associated with many other autoimune diseases, and even more frequently with the presence of circulating autoantibidies in the absence of clinical manifestations of their associated conditions Wingerchuk and Weinshenker foud autoimune diseases in $36 \%$ of 57 patients with relapsing NMO in only one $4 \%$ of 23 patients with monophasic NMO.

\section{CASE REPORT}

A 13-year-old patient, known to have a diagnosis of Dermatomyositis in 2015, when she started erythematous eruptions on the face (malar rash), bilateral periorbital regions (Heliotrope), elbows, knees and soles of the feet, and papulous, violet symmetrically distributed by the knuckles of the fingers (Gottron) and Proximal Muscle Weakness. In 2017, he evolved with total loss of vision one left eye and parcil in right eye, referring to blurred vision and discrete diplopia, Magnetic resonance imaging confirmed bilateral involvement of neuromyelitis optica. Treated as pulse therapy and immunoglubulin, maintaining ocular involvement. In 2018, despite treatment with pulse therapy and immunoglobulin, he started cervicalgia and pain in proximal musculature of MMSS, paresthesia in MSE and loss of strength in MMII. Cervical and thoracic RM demonstrated medullary inflammatory process (myelitis). The dosage of aquaporin was reagent. Multiple Sclerosis was away after negative search of Oligoclonal Bands. Initiated Mofetil Mocophenolate, with slight clinical improvement.

\section{CONCLUSION}

NMO has been associated with many autoimune diseases, The case report NMO appeared after 5 years of the diagnosis of Dermatomyositis, in spite of the specific treatment of the autoimmune disease established severely and with serious sequels. 